\title{
Morphology and Electrophysiology of Water Receptors on Legs of the Cricket Gryllus bimaculatus
}

\author{
Masamichi Kanou $^{1 *}$, Shinsuke Morita ${ }^{1 \ddagger}$, Tetsuya Matsuura ${ }^{1 \dagger}$ \\ and Tsuneo Yamaguchi ${ }^{2}$ \\ ${ }^{1}$ Department of Biology, Graduate School of Science and Engineering, \\ Ehime University, Matsuyama 790-8577, Japan \\ ${ }^{2}$ Kawasaki College of Allied Health Profession, Kurashiki, \\ Okayama 701-0194, Japan
}

\begin{abstract}
To identify the sensory organs that are sensitive to water stimuli in the cricket Gryllus bimaculatus, cuticular structures on the legs and the number of sensory neurons innervating them were studied. Some small hair sensilla on the legs were innervated by $2-5$ sensory neurons. All such sensilla had a tiny pore at the tip of their hairs. The diameter of the pore was approximately $0.2 \mu \mathrm{m}$. These findings suggest that these are chemosensitive hairs (LCS: leg chemosensillum). Of the three pairs of legs, the anterior legs (forelegs) possessed the largest number of LCSs. Of the five leg segments (i.e., coxa, trochanter, femur, tibia and tarsus), the tarsus possessed the largest number of LCSs on each leg. Electrophysiological investigation by tip recording revealed that some of the LCSs contained water-receptor cells. Because the basitarsus possessed a larger number of LCSs than the other tarsomeres, the distribution of water-receptor-containing LCSs in the basitarsus of a foreleg was investigated morphologically and electrophysiologically. LCSs that contained waterreceptor cells were mainly distributed on the ventral surface of the basitarsus. There were two types of water receptor that showed different response patterns to a stimulus, that is, phasic- and tonictype water receptors. From the distribution of LCSs on the legs, the roles of these different types of water receptors in behavioral selection, that is, the initiation of swimming and the inhibition of flying, will be discussed.
\end{abstract}

Key words: cricket, behavioral selection, water receptor, swimming, flying, tip recording

\section{INTRODUCTION}

Insects have been forced to "see" the external world through their thick cuticles. Therefore, they must have some cuticular structures that intercalate between the external world and sensory receptor cells. This is also true in the case of chemical sensing, including the sensing of water. In insects, most chemosensilla are hair shaped and are equipped with a number of receptor cells that respond to different types of chemicals, such as sugar, salt and water, and are also innervated by mechanoreceptor cells. In general, a large number of chemoreceptors are located near the mouth to discriminate edible and inedible materials. Such chemosensilla for tasting foods are also located on the tarsus of the legs in some insects, such as those belonging to the orders Lepidoptera, Diptera and Coleoptera (Bullock and Horridge, 1965). In these insects, most chemosensilla on the legs contain sugar receptors, and the insects show a proboscis-extension reflex when those chemosensilla come

\footnotetext{
* Corresponding author. Phone: +81-89-927-9631;

Fax : +81-89-927-9631;

E-mail: kanou@mserv.sci.ehime-u.ac.jp

† Present address: Department of Welfare Engineering, Faculty of Engineering, Iwate University, Morioka 020-8551, Japan

₹ The first two authors contributed equally to this work. doi: $10.2108 / z$ sj.24.953
}

into contact with foods containing sugar. This system ensures that the insects will take food quickly. In addition to such chemosensilla related to eating, other chemosensilla are located on insect legs, but their physiology and roles in mediating behaviors are poorly understood, except in a limited number of cases (White and Chapman, 1990; Newland, 1998).

Crickets react differently to an air puff stimulus applied to cercal filiform hairs, that is, running or jumping on the ground (Bentley, 1975; Gras and Hörner, 1992; Tauber and Camhi, 1995; Kanou et al., 1999), swimming when on a water surface (Matsuura et al., 2002), and flying when suspended in the air (Tomioka and Yamaguchi, 1980). Legablated crickets occasionally react to an air puff stimulus by flying even when they are placed on a water surface. What sensory information is required for such behavioral selection? Some sensory organs on the legs, such as hygroceptors or water receptors, are believed to have an important role in behavioral selection (Matsuura et al., 2002).

In the accompanying paper (Kanou et al., 2007), it was revealed that some sensory receptors on the legs play a significant role in the selection of swimming versus flying in the cricket Gryllus bimaculatus. The receptors likely mediate swimming and, at the same time, inhibit flying to some extent. Because the effect of applying an enamel coating to the leg surface was similar to that of leg ablation, these 
receptors were assumed to have structures on the cuticular surface. Therefore, the next step is to identify the sensory organs that control this behavioral selection.

In general, the water receptors of insects are usually attached to a hair-shaped cuticular structure together with other chemosensitive receptors such as the salt and sugar receptors as mentioned above. That is, the water receptors of insects are usually included in chemosensilla. In taste sensilla, the hair structure has a pore at its tip, through which stimuli such as water and chemicals arrive at the receptor site (e.g., Tominaga, 1975). These features are important clues that can be used to identify and investigate the distribution of chemosensilla which possibly possess water receptors.

In this study, we first observed hair sensilla on the legs after methylene blue staining and investigated the number of sensory neurons innervating them. After confirming that some of the sensilla are innervated by more than two sensory cells, the distribution of such hairs on the legs was investigated. Then, scanning electron microscopy (SEM) and electrophysiological experiments were performed on the sensilla to determine their external morphology and the electrical responses of water-receptor cells, respectively. The distribution of chemosensilla (LCSs) on the leg surface is discussed in relation to the results on behavioral changes after the ablation or enamel coating of legs reported in the accompanying paper (Kanou et al., 2007).

\section{MATERIALS AND METHODS}

\section{Animals}

Adult female crickets, G. bimaculatus, were used. They were reared in our laboratory and fed with insect chow (Oriental Kohbo) and carrots. The temperature of the culture room was in the range of $28-30^{\circ} \mathrm{C}$ and the LD cycle was $12: 12$. The details of cricket rearing were the same as in a previous study (Kanou and Kondoh, 2004).

\section{Neural staining}

Sensory neurons of hair sensilla on the legs were stained with methylene blue (MB) prepared using Unna's method as modified by MacConnell (Pantin, 1969). Crickets immediately after the final molt were used because their cuticles were not yet tanned or colored and stained sensory neurons could be observed through the cuticular exoskeleton (Fig. 1). The legs of crickets were isolated from the body, and $4-10 \%$ MB dissolved in saline solution (Kanou and Shimozawa, 1984) was injected with a needle inserted into the femur. To ensure the perfusion of the staining solution, one or two distal segments of the tarsus were ablated. In most cases, the neurons in the tibial and basitarsal segments were stained sufficiently for the investigation. After incubation in a refrigerator $\left(4^{\circ} \mathrm{C}\right)$ for more than $60 \mathrm{~min}$, a specimen was fixed in $7 \%$ ammonium molybdate for more than $3 \mathrm{~h}\left(4^{\circ} \mathrm{C}\right)$. After washing in running water for more than $3 \mathrm{~h}$, it was dehydrated in a standard graded alcohol series and was transferred to acetone. Then, it was transferred to monomeric stylol. The specimen was stored and observed in monomeric stylol.

\section{Scanning electron microscopy}

A cricket immediately after the final molt was isolated in a small container to avoid contaminating the cuticular surface of the legs. The legs were cut $24 \mathrm{~h}$ after the isolation because the exoskeleton had become sufficiently hard by that time. The legs were cleaned in acetone using supersonic waves. After drying in air, the specimen was fixed on a metal stage with an electroconductive paste (Dotite,
Fujikura,) and then sputter-coated with platinum-palladium. The leg surface, particularly the hair structures, was observed under a scanning electron microscope (JSM-6304F, JEOL).

\section{Electrophysiology}

The responses of the sensory neurons of hair sensilla were investigated using a typical tip-recording method (Hodgson et al., 1955). Glass capillaries filled with $\mathrm{NaCl}$ solutions of varying osmolarity $(1,3,10,30,100,300$ and $1000 \mathrm{mM})$ were sequentially mounted on a sensillum from the lowest-osmolarity solution to the highest-osmolarity solution with the aid of a micromanipulator. Lower-osmolarity solutions were sometimes tested again to ensure the physiological stability of a receptor cell (e.g., Fig. 4B). The $\mathrm{NaCl}$ solution in the glass capillary was a stimulus fluid, and, at the same time, worked as an electrolyte in the glass capillary. Therefore, responses of sensory neurons were obtained immediately after mounting the glass capillary on a cuticular hair. The recording usually lasted for 4-5 seconds per LCS. However, it was sometimes carried out for as long as 2-3 minutes to confirm the tonic nature of a receptor cell (see below). A steel rod was inserted into the body cavity as an indifferent electrode.

\section{RESULTS}

\section{Distribution of chemosensilla on legs}

The sensory neurons innervating hair structures on the cricket legs were observed after MB staining. Most of the hairs and spines on the legs were mechanosensilla, and only one bipolar sensory neuron innervated the base of the hair shaft. In addition to such mechanosensitive hairs, small hairs innervated by 2-5 sensory neurons were also observed (Fig. 1). The distal ends of such sensory neurons extended into the hair shaft and almost reached the tip of the hairs. Sometimes, such small hairs were aligned along the longitudinal axis of a leg segment (e.g., Fig. 3B). The number of sensory cells attached to a hair structure varied, and there was no clear relationship between the position of a hair and the number of sensory neurons innervating it.

$A$ hair sensillum innervated by more than two sensory

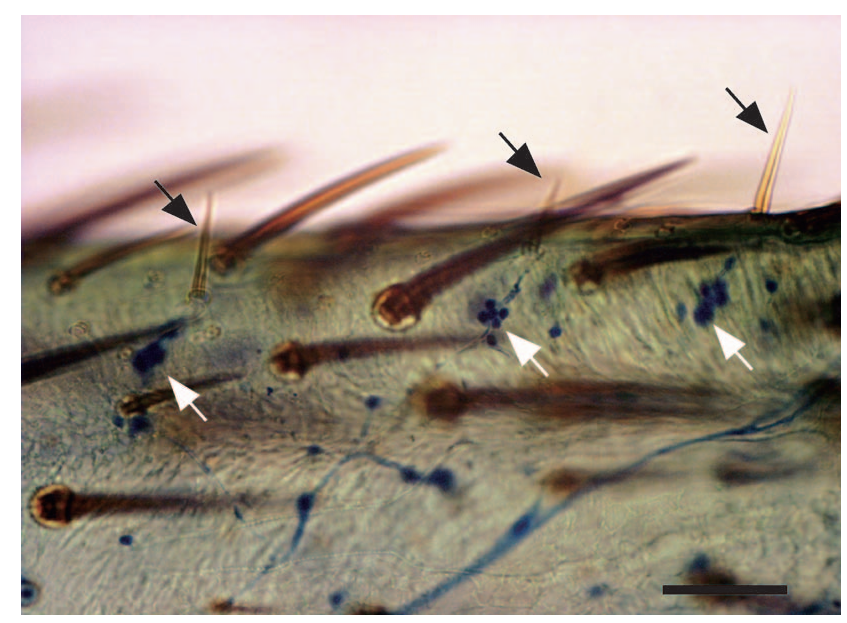

Fig. 1. LCS hairs on the basitarsus and their sensory cells stained with MB. LCSs are aligned along the longitudinal axis of the leg segment. Each LCS hair (black arrows) is innervated by 3-5 sensory cells (white arrows). Note that the angles between the LCS hairs and the cuticular surface are larger than those for other hairs. Scale bar, $50 \mu \mathrm{m}$ 
cells is a typical chemosensillum in insects (e.g., Eckert and Randall, 1978). Therefore, we tentatively refer to such sensilla found on cricket legs as LCSs (leg chemosensilla). Most of the hairs on cricket legs other than LCS hairs stood on the leg surface at an angle of $30-45^{\circ}$. In contrast, LCS hairs stood more vertically, at angles larger than $60^{\circ}$ (Figs. $1,2 A)$. Owing to such morphological features, we could easily distinguish LCSs from other hairs without staining their sensory neurons. Thus we were able to count the number of LCSs on leg segments in unstained specimens under the microscope (Table 1). The numbers of LCSs on the fore-

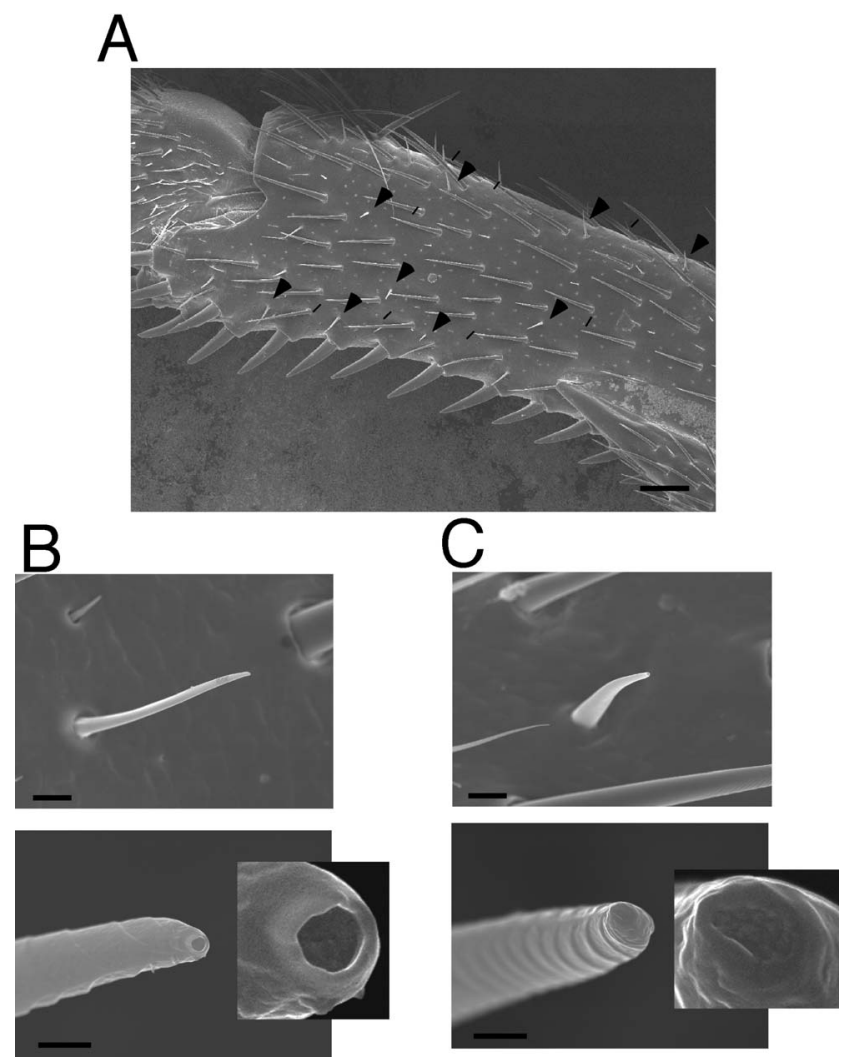

Fig. 2. Scanning electron micrographs of LCS hairs on cricket legs. (A) Distal part of basitarsus of right foreleg. Some LCSs are indicated by arrowheads; they stand more vertically than the other hairs. (B) Middle-sized (approximately $50 \mu \mathrm{m}$ ) and (C) short-sized approximately $22 \mu \mathrm{m}$ ) LCSs. They are bent slightly at the tip. Ringor spiral-shaped lines are observed on the external surface of the hairs. Each hair has a pore with a diameter of approximately $0.2 \mu \mathrm{m}$ at its tip. Scale bars, $100 \mu \mathrm{m}$ in $A ; 10 \mu \mathrm{m}$ for upper photos in $\mathrm{B}$ and C; $1 \mu \mathrm{m}$ for lower photos in B and C. legs, middle legs and hindlegs were $311.5 \pm 57.7,252.5 \pm 23.2$ and $214.5 \pm 36.0$, respectively. Significant differences were observed in the number of LCS hairs between every pair of legs $(P<0.05)$. The anterior legs thus possessed the largest number of LCSs, even though these legs are smaller than the other legs. On every leg, the total number of LCSs on the entire tarsal segment was greater than on other segments, even though the tarsus was smaller than the other segments. The total numbers of LCSs on the tarsus was $124.8 \pm 29.0,119.5 \pm 21.4$ and $106.7 \pm 13.2$ for the fore-, middle and hindlegs, respectively. Among the four tarsomeres (Fig. $3 \mathrm{~A}$ ), the basitarsus (the most proximal tarsomere) possessed the largest number of LCSs for each leg, that is, $68.0 \pm 12.7,63.3 \pm 11.1$ and $38.8 \pm 31.1$ for the fore-, middle and hindlegs, respectively (Table 1 ). The number and distribution of LCSs differed from individual to individual to some extent.

\section{SEM observation of LCS hairs}

The external structures of LCS hairs were investigated by SEM observation (Fig. 2). The large angle between LCS hairs and the leg surface mentioned above allowed us to distinguish them from other hairs even during SEM observation (Fig. 2A). The length of LCS hairs varied from 30 to 100 $\mu \mathrm{m}$. However, there was no clear relationship between the length of the hairs and their position on the legs. Relatively long hair shafts were almost straight, but the tip of relatively shorter hair shafts bent slightly in most cases. Every LCS hair had a pore with a diameter of approximately $0.2 \mu \mathrm{m}$ at its tip, and many ring- or spiral-shaped lines were observed on the external surface of the hairs (Fig. 2B, C).

\section{Water-receptor cells in LCSs}

The neural response of the sensory cells in LCSs was studied by tip recording. In most LCSs, the responses of a mechanoreceptor cell were recorded immediately after the glass electrode covered the hair. In addition, responses of sensory cells to $\mathrm{NaCl}$ were also recorded from many LCSs (salt spikes). However, we did not perform a detailed investigation on such cells because our aim was to confirm the presence and distribution of water-receptor-containing LCSs. Among the responses of such mechanoreceptors and salt receptors, neurons in some LCSs responded to lowosmolarity $\mathrm{NaCl}$ solutions (e.g., 1, 3 and $10 \mathrm{mM} \mathrm{NaCl}$ ), but showed no response to high-osmolarity $\mathrm{NaCl}$ solutions (e.g., 30 and $100 \mathrm{mM} \mathrm{NaCl}$ ) (Fig. 4). This is a typical physiological characteristic of water-receptor cells in insects (e.g., Hiroi et al., 2002).

Electrical responses were recorded from as many LCSs

Table 1. Number of LCSs on legs.

\begin{tabular}{|c|c|c|c|c|c|c|c|c|c|c|c|}
\hline & & & Tarsus & & & Tibia & Femur & Trochanter & Coxa & Total & $\mathrm{N}$ \\
\hline & Claw & T3 & $\mathrm{T} 2$ & Basitarsus & Total & & & & & & \\
\hline Foreleg & $3.8 \pm 3.4$ & $42.2 \pm 14.1$ & $10.8 \pm 3.6$ & $68.0 \pm 12.7$ & $124.8 \pm 29.0$ & $76.0 \pm 18.4$ & $85.5 \pm 10.0$ & $6.3 \pm 2.0$ & $18.8 \pm 6.3$ & *311.5 \pm 57.7 & 6 \\
\hline Middle leg & $8.5 \pm 2.9$ & $39.7 \pm 9.5$ & $8.0 \pm 2.3$ & $63.3 \pm 11.1$ & $119.5 \pm 21.4$ & $58.2 \pm 9.8$ & $59.7 \pm 19.1$ & $4.8 \pm 0.8$ & $10.3 \pm 7.5$ & ${ }^{\star} 252.5 \pm 23.2$ & 6 \\
\hline Hindleg & $4.7 \pm 2.6$ & $26.4 \pm 17.0$ & $6.2 \pm 3.9$ & $38.8 \pm 31.1$ & $106.7 \pm 13.2$ & $56.5 \pm 19.5$ & $46.0 \pm 23.7$ & 0.0 & $5.3 \pm 2.7$ & ${ }^{*} 214.5 \pm 36.0$ & 6 \\
\hline
\end{tabular}

Values given are means \pm SDs.

A tarsus consists of four tarsomeres (basitarsus, T2, T3 and claws). Refer to Fig. 3 for the names of the tarsomeres.

${ }^{*}$ Asterisk: significant difference $(P<0.05)$ between total number of LCSs on every pair of leg. 

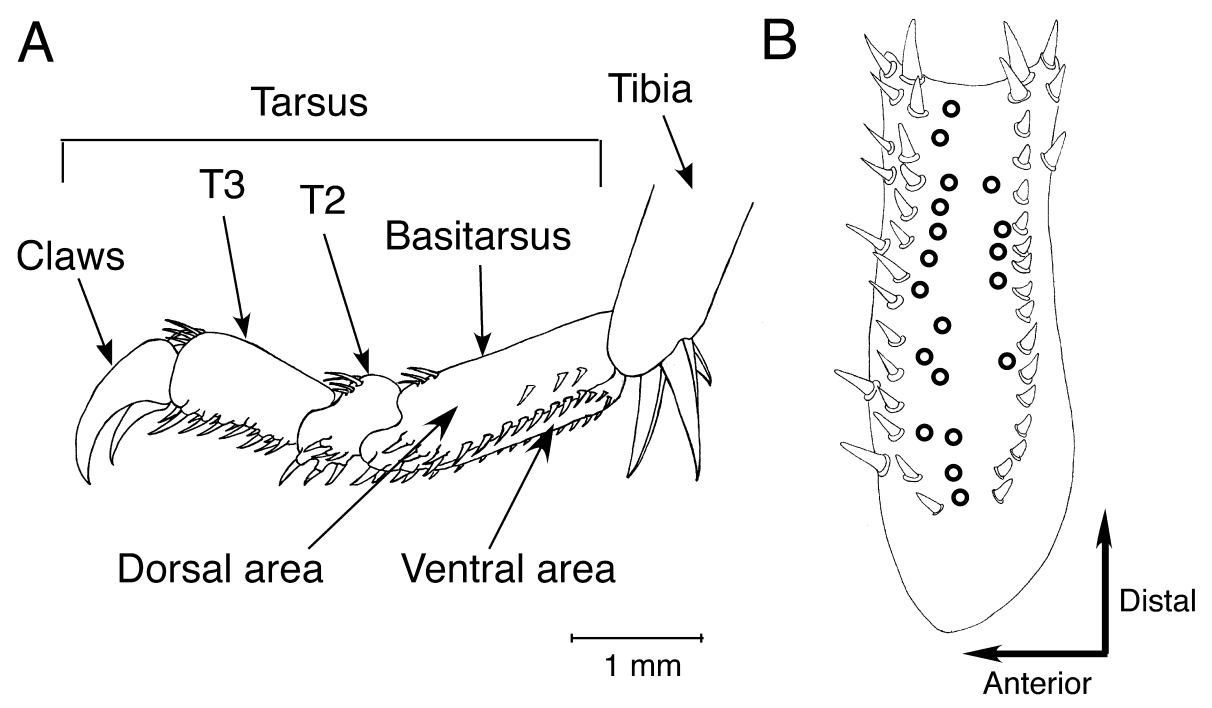

Fig. 3. (A) Side view of distal parts of foreleg. The boundaries between the dorsal and ventral areas of the basitarsus are the two rows of spines at the bottom margin of the segment (see B). The tarsus consists of four tarsomeres: basitarsus, T2 (second tarsomere), T3 (third tarsomere), and claws. (B) Ventral view of basitarsus showing two rows of spines. These rows are the boundaries between the dorsal and ventral areas. Circles indicate the positions of the LCSs on this specimen.

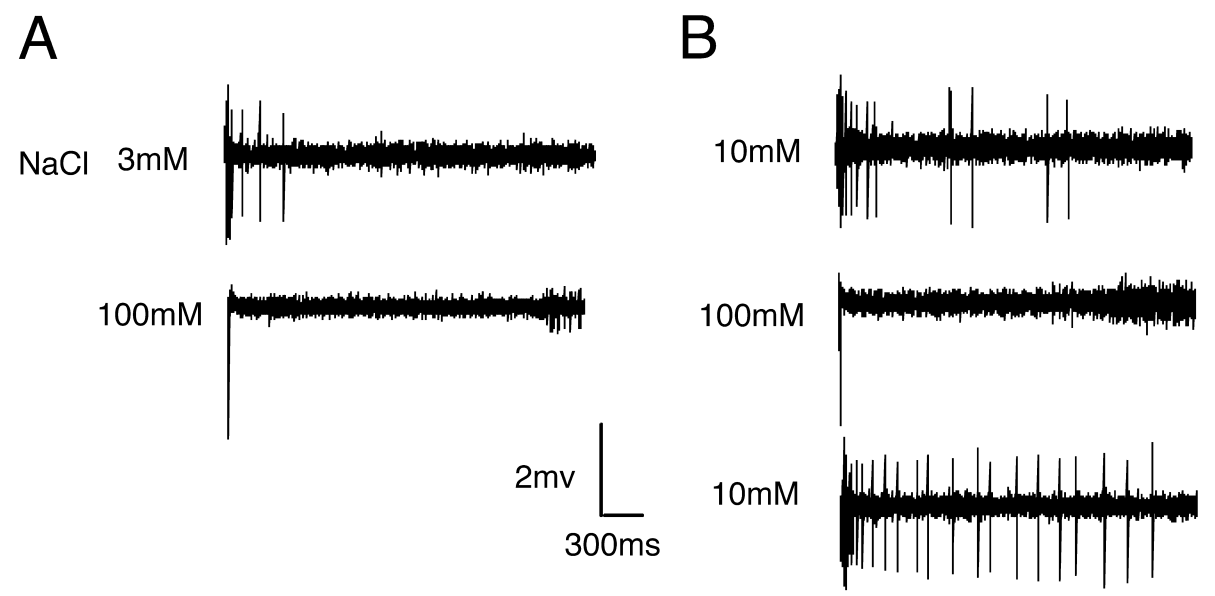

Fig. 4. Examples of responses of phasic-type (A) and tonic-type (B) water-receptor cells to $\mathrm{NaCl}$ solutions. Stimuli were continuously applied to the LCSs while recording. (A) Responses of the phasic-type water-receptor cell to $\mathrm{NaCl}$ solutions. The response to $3 \mathrm{mM} \mathrm{NaCl}$ (upper trace) disappeared for $100 \mathrm{mM} \mathrm{NaCl}$ (lower trace). The spike-shaped potential at the beginning was an artifact, and small spikes at the end of the record were not from water-receptor cells. (B) Responses of the tonic-type water-receptor cell to $\mathrm{NaCl}$ solutions of different osmolarity. The response to $10 \mathrm{mM} \mathrm{NaCl}$ (upper trace) disappeared for $100 \mathrm{mM} \mathrm{NaCl}$ (middle trace). However, the receptor cell responded when the solution was again changed to $10 \mathrm{mM}$ (lower trace). The tonic feature of the cell is clearer in the lower trace.

as possible on the basitarsus of the forelegs to investigate the distribution of water-receptor-containing LCSs (Table 2), because this segment possessed the largest number of LCSs among all the leg segments (Table 1). The surface of the basitarsus was roughly divided into two areas, that is, the ventral and dorsal areas (Fig. 3). In each area, LCSs were randomly chosen and electrical responses to a water stimulus were recorded. However, owing to the difference in the degree of difficulty in approaching LCS hairs depending on their position, the numbers of LCSs investigated in the two areas differed (110 vs 61 ; Table 2 ). Water-receptor cells were identified in $46.3 \%$ (51 of 110 ) and $32.8 \%$ (20 of 61 ) of the LCSs located in the ventral and dorsal areas, respectively (Table 2). The ratio of LCSs that contained water- receptor cells to the total LCSs in the ventral area was thus larger than that in the dorsal area of the basitarsus.

The response patterns of the water-receptor cells investigated in this study could be divided into two types, namely, phasic type (Fig. 4A) and tonic type (Fig. 4B). The phasictype receptors responded to water only at the beginning of stimulation. On the other hand, the tonic-type neurons showed long-lasting responses during stimulation. Although the phasic or tonic nature of a receptor cell could be ascertained by a $4-5 \mathrm{sec}$ recording, we sometimes carried out recordings for as long as $2-3 \mathrm{~min}$ to ensure the tonic feature of some sensory cells. Tonic-type water receptors continued to respond during such long recordings even though the spiking frequencies showed changes to some extent. 
Table 2. LCSs on basitarsus that contained water-receptor cells.

\begin{tabular}{lccc}
\hline & $\begin{array}{l}\text { Numbers of LCSs } \\
\text { investigated }\end{array}$ & $\begin{array}{l}\text { Numbers of LCSs with } \\
\text { water receptor cells }\end{array}$ & $\%$ \\
\hline Ventral area & 110 & $51(33+18)$ & 46.3 \\
Dorsal area & 61 & $20(10+10)$ & 32.8 \\
\hline
\end{tabular}

In parentheses are the numbers of phasic-type and tonic-type water receptors, respectively.

$\%$ for each area: percentage of LCSs that contained waterreceptor cells.

Among the 71 water receptors investigated in the ventral and dorsal areas, 43 receptor cells $(60.6 \%)$ were phasic type; the remaining 28 receptor cells (39.4\%) were tonic type (Table 2).

\section{DISCUSSION}

Chemosensilla on the legs and their contributions to evoking behaviors have been reported in some orthopteran insects, (Schistocerca americana: White and Chapman, 1990; Schistocerca gregaria: Newland, 1998). In crickets, it has also been reported that the nymphs of Gryllus domesticus (Acheta domesticus) possess hair sensilla innervated by four sensory cells on all leg segments except the tarsus (Fudalewicz-Niemczyk et al., 1980). The sensilla were 9-28 $\mu \mathrm{m}$ long, slightly bent on the tip, and blunt ended. On the basis of the number of sensory cells equipped, they were considered to be chemosensilla. However, the physiological characteristics and the roles of the chemosensilla in evoking a particular behavior in the crickets have not yet been studied.

In G. bimaculatus, we focused on hair sensilla on the legs that possessed 2-5 sensory cells (Fig. 1), even though it was uncertain whether they were homologous with those reported in G. domesticus (Fudalewicz-Niemczyk et al., 1980). By SEM observation, a tiny pore was confirmed at the tip of such hair sensilla (Fig. 2B, C). This is definite evidence that the hairs are chemosensitive. They are similar to the taste sensillum, which has a pore at the hair tip, and different from the olfactory sensillum, which has many minute pores on the wall side of the hair (e.g., Eckert and Randall, 1978; Kaissling, 1971). However, the external surface of LCS hairs was quite different from that of the typical taste labellar hairs of flesh flies (Tominaga, 1975). The external surface of the labellar hairs is longitudinally grooved, whereas the LCS hairs showed a ring- or spiralshaped surface (Fig. 2B, C).

Although there was size and shape variation among the LCS hairs, we could not find any relationship between their size or position and the number of sensory cells attached. We were also not able to identify any functional difference among them. The morphologies of cuticular structures sometimes have a relationship with the physiological features of the sensory cells attached. In the labellar chemosensitive hairs in Drosophila, for example, hair size is clearly associated with the type of sensory receptor cell, that is, with a difference in response pattern between sugar and sucrose stimulation (Hiroi et al., 2002). Therefore, the morphological differences of LCSs in G. bimaculatus may be associated with some physiological characteristics of their receptor cells.
Water-receptor cells in LCSs could be identified from their characteristic patterns of response to $\mathrm{NaCl}$ solutions of different concentrations. They responded to lower $\mathrm{NaCl}$ concentrations than those at which salt receptors responded, and the responses were inhibited by stimulation with solutions of high osmolarity (Fig. 4). In this study, two types of water-receptor cell were found on the cricket legs, namely phasic type and tonic type. Although we could not confirm the roles of these receptors, there might be some role sharing between them due to different rates of adaptation to water stimuli. For example, tonic-type water receptors might be essential for the crickets to continue swimming by continuously providing information on water. On the other hand, phasic-type receptors might be used in triggering swimming or in a rapid reflex-like behavior similar to the leg withdrawal reflex in the locust (Newland, 1998).

This study confirmed that a larger number of LCSs are present on the surface of the forelegs than on the other legs (Table 1). On every leg, the total number of LCSs on the tarsus was larger than on the other segments. In the accompanying paper (Kanou et al., 2007), it was shown that the initiation of swimming and the inhibition of flying are caused by inputs from sensory organs on the leg surface. Among the three pairs of legs, the sensory inputs from the forelegs are stronger than those from other legs, and among the segments of all the legs, the sensory inputs from the tarsal segments are stronger than those from the other segments for swimming initiation and flying inhibition. The distribution of LCSs on the leg surface revealed in this study explains that the behavioral changes observed in crickets, that is, a decrease in the occurrence of swimming and an increase in the occurrence of flying during sequential ablation of the legs and leg segments (Kanou et al., 2007), were due to a decrease in the number of LCSs.

In the accompanying paper, sequential leg-segment ablation showed that the relative occurrence of flying still increased after the ablation of the femora in only hindlegintact crickets (Kanou et al., 2007). However, in only forelegor middle leg-intact crickets, the relative occurrence of flying showed no change after the ablation of the femoral segment. This may suggest that the sensory organs on the femoral segment of the hindlegs prevent flying more effectively than other legs. This is interesting, since the number of LCSs on the femur of the hindlegs was smallest among the three pairs of legs (Table 1). We assume that this may be because the total number of LCSs on the hindlegs was also the smallest among the legs. In this case, the effectiveness of each LCS on behavioral selection must be larger. In other words, each sensory organ on the femoral segment of the hindlegs prevents flying more effectively than the LCSs on other legs, even though the total number of LCSs on the segment is small.

In this study, it was also revealed that the ratio of LCSs containing water-receptor cells to the total LCSs was larger on the ventral side of the basitarsus than on the dorsal side (Table 2). The legs of adult crickets usually sink in the water when the insects are placed on the water surface. Therefore, water receptors on the legs are stimulated regardless of their position on the leg surface. However, the legs of younger nymphs float on the water during swimming, owing to the surface tension of water, because the nymphs are 
light in body weight. In such small nymphal crickets, only the ventral surface of the legs touches the water, and water receptors on the ventral side must solely be stimulated. Therefore, the distribution pattern of water receptors on the legs explains the necessity of the information from such receptors for behavioral selection, particularly in nymphal crickets.

\section{ACKNOWLEDGEMENTS}

We thank K. Yasuyama, K. Uehira, and Y. Suda of Kawasaki Medical School for the use of their scanning electron microscope. We also thank T. Tanimura of Kyushu University and the members of his laboratory for their technical assistance in electrophysiology of LCSs. This work was partially supported by grants to M. K. from the Japan Society for the Promotion of Science and the Japanese Ministry of Education, Culture, Sports, Science and Technology.

\section{REFERENCES}

Bentley D (1975) Single gene cricket mutations: effects on behavior, sensilla, sensory neurons, and identified interneurons. Science 187: 760-764

Bullock TH, Horridge GA (1965) Structure and Function in the Nervous Systems of Invertebrates. WH Freeman and Company, San Francisco

Eckert R, Randall D (1978) Animal Physiology. WH Freeman and Company, San Francisco

Fudalewicz-Niemczyk W, Oleksy M, Rosciszewska M (1980) The peripheral nervous system of the larva of Gryllus domesticus L. (Orthoptera). Part III. Legs. Acta Biol Cracoviensia Ser Zool 22: $51-63$

Gras H, Hörner M (1992) Wind-evoked escape running of the cricket Gryllus bimaculatus. I. Behavioral analysis. J Exp Biol 171: 189-214

Hiroi M, Marion-Poll F, Tanimura T (2002) Differentiated response to sugars among labellar chemosensilla in Drosophila. Zool Sci 19: $1009-1018$

Hodgson ES, Lettvin JY, Roeder KD (1955) Physiology of a primary chemoreceptor unit. Science 122: 417-418
Kaissling K-E (1971) Insect olfaction. In "Handbook of Sensory Physiology Vol 6" Ed by LM Beidler, Springer-Verlag, Berlin , pp 358-365

Kanou M, Kondoh Y (2004) Compensation of escape direction in unilaterally cercus-ablated crickets, Gryllus bimaculatus, is associated with the distance walked during recovery period. Zool Sci 21: 933-939

Kanou M, Shimozawa T (1984) A threshold analysis of cricket cercal interneurons by an alternating air current stimulus. J Comp Physiol A 154: 357-365

Kanou M, Ohshima M, Inoue J (1999) The air-puff evoked escape behavior of the cricket Gryllus bimaculatus and its compensational recovery after cercal ablations. Zool Sci 16: 71-79

Kanou M, Morita S, Matsuura T, Yamaguchi T (2007) Analyses of behavioral selection after sensory deprivation of legs in the cricket, Gryllus bimaculatus. Zool Sci 24: 945-952

Matsuura T, Kanou M, Yamaguchi T (2002) Motor program initiation and selection in crickets, with special reference to swimming and flying behavior. J Comp Physiol A 187: 987-995

Newland PL (1998) Avoidance reflexes mediated by contact chemoreceptors on the legs of locusts. J Comp Physiol A 183: 313-324

Pantin CFA (1969) Notes on Microscopical Technique for Zoologists. Cambridge University Press, Cambridge, pp 54-55

Tauber E, Camhi JM (1995) The wind-evoked escape behavior of the cricket Gryllus bimaculatus: integration of behavioral elements. J Exp Biol 198: 1895-1907

Tominaga $Y(1975)$ The taste pore of the fleshfly labellar hair. $J$ Electron Microsc 24: 171-174

Tomioka K, Yamaguchi T (1980) Steering responses of adult and nymphal crickets to light, with special reference to the head rolling movement. J Insect Physiol 26: 47-57

White PR, Chapman RF (1990) Tarsal chemoreception in the polyphagous grasshopper Schistocerca americana: behavioural assays, sensilla distributions and electrophysiology. Physiol Entomol 15: 105-121

(Received October 29, 2006 / Accepted June 4, 2007) 